\title{
Tradução de quadrinhos: uma reflexão sobre a identidade cultural pelo viés do estereótipo do judeu na linguagem dos quadrinhos
}

\section{Comics translation: a reflection upon the cultural identity considering the Jew stereotype in the language of comics}

\author{
Gisele Marion Rosa*
}

Resumo: Em uma narrativa como a história em quadrinhos, em que se encontra uma relação de interdependência entre texto e imagem na construção do significado, parece-nos mais provável que as estratégias recorrentes de tradução recaiam na literalidade (VINAY \& DALBERNET 1995), pois o texto verbal, em princípio, não poderia contradizer a ilustração que o acompanha, mas sim manter a relação estabelecida entre os dois códigos encontrada no original. Além disso, consideramos um aspecto central da formação do gênero Quadrinhos o caráter de inovação em relação às normas vigentes da linguagem verbal e não verbal, do ponto de vista da sua criação artística, onde temos "uma hibridização bem-sucedida de ilustração e prosa" (EISNER 2010). Desse modo, a linguagem inovadora e potencialmente plástica desse gênero, devido à liberdade de criação, propicia um espaço ideal para tratar de temas sensíveis e que instigam o debate e reformulação de conceitos enraizados numa dada cultura. Isto posto, propomos apresentar brevemente os dados de nossa investigação sobre como se dá o tratamento do estereótipo do judeu para o estudo da identidade cultural em um estudo de caso, a tradução de A História dos Judeus, de Stan Mack. Defendemos que a fruição de um objeto cultural na linguagem dos quadrinhos, quando traduzido e atravessando fronteiras, resulta numa comunicação intercultural

\footnotetext{
"Tradutora e Mestre em Semiótica e Linguística Geral (2010) pela Faculdade de Filosofia, Letras e Ciências Humanas (FFLCH/USP).
} 
RosA, G. M. - Tradução de quadrinhos: uma reflexão sobre a identidade cultural pelo viés do estereótipo judeu na linguagem dos quadrinhos

que promove o diálogo, a evolução de pensamentos, conceitos e modos de ver o mundo pelo contato com o Outro numa velocidade maior do que aquela encontrada na leitura de livros em prosa. Procuramos identificar, assim, se a tradução apresentou uma tendência ao esvaziamento do estereótipo ou sua legitimação na construção do sentido. Ou em outras palavras, investigar se houve nas traduções uma revisão do estereótipo apresentado nas obras originais. Para tanto, foi feito o levantamento dos itens lexicais e elementos da ilustração que se referem ao universo da cultura judaica e analisamos o modo como eles são trazidos para as traduções.

Palavras-chave: Estereótipo do judeu; identidade cultural; história em quadrinhos; Estudos da Tradução.

Abstract: In a narrative such as comics, in which there is an interdependent relationship between text and image in the construction of meaning, it seems more likely that translation strategies tend to be more literal (Vinay \& Dalbernet 1995). This idea exists because the verbal text, in principle, could not contradict the illustration that accompanies it, but it should keep the relationship established between the two codes found in the original. Also, we consider the nature of innovation in relation to existing rules of verbal and nonverbal languages a central aspect of formation of Comics, from the point of view of its artistic creation, since we have "a successful hybridization between illustration and prose" (Eisner 2010). Thus, the innovative and potentially plastic language of comic books, due to the freedom of creation, provides an ideal space to deal with sensitive issues and instigate debate and reformulation of concepts rooted in a given culture. That said, we will briefly present the data from our research on how the treatment of the Jewish stereotype is for the study of cultural identity in a case study: the translation of The History of the Jews, Stan Mack. We argue that the enjoyment of a cultural object in the language of comics, when translated and across borders, results in intercultural communication that promotes dialogue, the evolution of thoughts, concepts and ways of seeing the world through contact with the Other in a higher speed than the one found in reading prose books. Thus, we seek to identify if the translation had a tendency to take out the stereotype or legitimate it in the construction of meaning. In other words, we want to investigate whether there was, in the translation, a review of the stereotypes present in the original works. We analyzed the lexical items and graphic elements that refer to the universe of Jewish culture and analyzed how they were brought to the translation.

Keywords: Jew stereotype; cultural identity, comics; Translation Studies

TradTerm, São Paulo, v. 27, Setembro/2016, pp. 217-246

www.usp.br/tradterm

http://www.revistas.usp.br/tradterm/index 
RosA, G. M. - Tradução de quadrinhos: uma reflexão sobre a identidade cultural pelo viés do estereótipo judeu na linguagem dos quadrinhos

\section{Introdução}

A leitura de uma obra narrativa que traz a linguagem dos quadrinhos pode ser feita de diversas formas devido à enorme liberdade que seu potencial de criação promove. Por exemplo, a direção da leitura pode ser de trás para frente, como nos mangás, ou as passagens de tempo e espaço podem variar de acordo com os inúmeros estilos possíveis pela visão dos artistas. Como, por exemplo, o instante de uma ação corriqueira, como acender um cigarro, pode ser representado em um único quadrinho, ou em uma sequência de quadrinhos ao ocupar uma página inteira, ou simplesmente ser suprimido, dependendo principalmente da liberdade de criação do ilustrador. Essa versatilidade na criação também se encontra no formato com que essa obra pode ser editada: livros, tiras de jornal ou, até mesmo, a reedição em formatos diferentes, ora revistas, ora a reunião das mesmas em formato livro, inclusive transpostas para o meio digital.

No entanto, independente da elaboração temática, estrutural ou da recepção material dessa obra, a construção do significado passa, necessariamente, por dois códigos, o verbal e o não-verbal. Ainda que um quadrinho apresente apenas ilustrações e nenhum texto verbal, ou o contrário, um texto venha desacompanhado de ilustração, no espaço do quadrinho teremos sempre uma leitura cuja construção de sentido é feita por uma linguagem que, na verdade, incorporou duas outras. ${ }^{1}$ Compreendemos, assim, que a relação interdependente entre esses códigos para interpretação do sentido é única e autônoma, apesar de dialogar, naturalmente, com várias outras expressões culturais, como o cinema, a fotografia e, claro, a literatura.

\footnotetext{
${ }^{1}$ Fazemos referência, nesse trecho, a textos dentro de balões de fala em que o próprio traço que os circundam já trazem uma informação semântica que pode mudar completamente o significado do texto, se lido separadamente, já que uma imagem pode ser lida como um texto e vice-versa Cf. Cagnin 1975; Ramos 2009b.
}

TradTerm, São Paulo, v. 27, Setembro/2016, pp. 217-246

www.usp.br/tradterm

http://www.revistas.usp.br/tradterm/index 
RosA, G. M. - Tradução de quadrinhos: uma reflexão sobre a identidade cultural pelo viés do estereótipo judeu na linguagem dos quadrinhos

Dessa forma, reconhecemos o potencial versátil e a liberdade de criação presentes na linguagem dos quadrinhos e elegemos as narrativas em quadrinhos como um espaço de produção cultural ideal para tratar de temas sensíveis na área dos Estudos da Tradução. Isso porque nos parece mais provável que as estratégias recorrentes de tradução tendam para a tradução literal (VINAY \& DALBERNET 1995) nessa relação de interdependência entre texto e imagem na construção do significado. Essa hipótese, naturalmente, parte de generalizações feitas nos primeiros contatos dessa investigação nesse tipo de narrativa e que pretendemos, em estudos posteriores, desdobrá-la e assim complementá-la.

Com isso, desperta-nos o interesse em investigar as possíveis limitações e tendências das estratégias tradutórias, uma vez que o texto verbal, em princípio, não poderia contradizer a ilustração que o acompanha, mas sim manter a relação estabelecida entre os dois códigos encontrada no original. Propomos investigar neste artigo como se dá o tratamento do estereótipo do judeu, conceito nuclear de análise, selecionado para o estudo da identidade cultural em um estudo de caso, a tradução de A História dos Judeus, de Stan Mack.

Ainda, o ambiente de recepção para o qual o livro original e sua tradução foram escritos abrange os Estados Unidos e o Brasil. Ambos os países e respectivas culturas têm em sua formação social, em maior ou menor grau, a expressiva imigração dos povos judeu e árabe. No cenário mundial, portanto, revela-se igualmente importante o contexto geopolítico problemático dos conflitos entre Palestina e Israel, despertando o interesse de pesquisadores das áreas de língua e literatura sobre o discurso da intolerância. Defendemos que a fruição desse objeto cultural, a narrativa em quadrinho, quando traduzido e atravessando fronteiras, resulta numa comunicação intercultural que promove o diálogo, a evolução de pensamentos, conceitos e modos de ver o mundo pelo contato com o Outro 
RosA, G. M. - Tradução de quadrinhos: uma reflexão sobre a identidade cultural pelo viés do estereótipo judeu na linguagem dos quadrinhos

numa velocidade maior do que aquela encontrada na leitura de livros em prosa.

Vemos, portanto, o entrelaçamento das motivações centrais para a execução desta investigação com a escolha do corpus para análise: a ascensão de um objeto cultural na esfera da práxis da leitura que trata em sua temática questões sensíveis, como aquelas encontradas no discurso da intolerância. Assim, este trabalho poderia abordar com naturalidade a representação da identidade cultural de diversos outros grupos minoritários como, por exemplo, o estereótipo do negro, da mulher, do homossexual, do árabe, etc. É justamente o aspecto que envolve diretamente a discussão de questões sociais representadas na Indústria Cultural que justifica a escolha do estereótipo do judeu, e que nos instiga a desenvolver este trabalho.

\section{A sobreposição das questões de identidade às questões ideológicas nos Estudos da Tradução}

“(...) a tradução constitui um dos principais meios pelo qual a cultura é construída e, portanto, é importante para qualquer estudo sobre evolução cultural e formação da identidade"

(GENTZLER 2008: 2)

Ao nos deparmos com a epígrafe acima, é possível observar uma importante reflexão que é tecida no diálogo entre o conceito de tradução e as

\footnotetext{
2 "translation constitutes one of the primary means by which culture is constructed and is therefore important to any study of cultural evolution and identitity formation". - tradução nossa.
}

TradTerm, São Paulo, v. 27, Setembro/2016, pp. 217-246

www.usp.br/tradterm

http://www.revistas.usp.br/tradterm/index 
RosA, G. M. - Tradução de quadrinhos: uma reflexão sobre a identidade cultural pelo viés do estereótipo judeu na linguagem dos quadrinhos

questões culturais que ganharam destaque nas recentes pesquisas dentro dos Estudos da Tradução: a questão da identidade.

De acordo com Gentzler (2008: 3), a abordagem teórica que vem ganhando destaque "enfoca, frequentente, grupos oprimidos e minorias dentro de culturas, destacando o papel cultural que as políticas de tradução desempenham no processo discriminatório". Consideramos, portanto, que o ponto de vista que privilegia essas questões sociais em sua investigação dentro dos Estudos da Tradução dialoga diretamente com as motivações que deram início à nossa pesquisa: descrever e compreender melhor o discurso da intolerância. Dessa forma, com base no crescente interesse de pesquisadores em investigar como essas minorias estão sendo retratadas nas traduções, uma vez que vários estudos apontam para a responsabilidade imbuída no ato de traduzir, elegemos as questões de identidade cultural para descrever e analisar traduções de narrativas em quadrinhos.

Defendemos, portanto, que a tradução nunca será um ato isolado, pois está cercada de diferentes agentes com propósitos específicos, como vemos nas palavras de Hermans: "do ponto de vista da literatura da língua meta, todas as traduções implicam um certo nível de manipulação do texto fonte por um propósito específico”4 (1985: 11). Ainda, a tradução traz em si uma gama de potencialidade em disseminar ideias, conceitos e descrições de determinados grupos, ou melhor, contribui para a perpertuação de identidades ou para um questionamento ao reformular conceitos enraizados em uma cultura.

É precisamente a capacidade que a tradução tem em provocar questionamentos e revisões de conceitos estereotipados entre-culturas que

3 "this study frequently focuses on minority and oppresses groups within cultures and highlights the cultural role translation policies play in the discriminatory process" - tradução nossa.

4 "From the point of view of the target literature, all translation implies a certain degree of manipulation of the source text for a certain purpose" - tradução nossa. 
RosA, G. M. - Tradução de quadrinhos: uma reflexão sobre a identidade cultural pelo viés do estereótipo judeu na linguagem dos quadrinhos

pretendemos refletir aqui, isto é, a possibilidade de a tradução repensar estereótipos quando apresenta transparência de objetivos por parte dos agentes envolvidos, promovendo representações mais justas à realidade de grupos minoritários.

(...)a tradução não é um espaço neutro nas Américas, pelo contrário, é um local de grande disputa onde grupos diferentes sempre em competição literária ou de interesses políticos, rivalizam pelo espaço e pela aprovação. (...) aqueles que perdem sofrem diversas consequências, incluindo a marginalização social, a perda de identidade e o trauma psicológico. (GENTZLER 2008:3) ${ }^{5}$

Podemos ver, então, que a questão da identidade está efetivamente presente e no cerne dessa nova abordagem dos Estudos da Tradução, em especial nas Américas onde se encontram os livros selecionados para esta pequisa. Os principais aspectos em se pensar nos impactos sofridos por grupos minoritários passam pela escolha daquilo que está sendo traduzido e, principalmente, daquilo que não está. “(...) Aqueles que decidem as políticas culturais e linguísticas também decidem a política da tradução que, por sua vez, afetam herança textual, preservação e disseminação" (ibidem) ${ }^{6}$. Desse modo, essas escolhas que escapam da autonomia do tradutor promovem abertura ou o fechamento de espaços de diálogo e conhecimento de certas culturas dentro desse continente multifacetado.

Entretanto, observamos, por outro lado, narrativas cuja linguagem se mostra capaz de reelaborar imagens estereotipadas presentes nessa relação intercultural com base nos seus recursos de criação. Como veremos especificamente na imagem do judeu que circula entre os Estados Unidos e o

\footnotetext{
5 “(...) translation is not a neutral site in the Americas, rather, it is a highly contested one where different groups, often with competing literary or political interests, vie for space and approval. (...) those who lose suffer many consequences, including social marginalization, loss of identity and psychological trauma" - tradução nossa.

6 "(...) those who decide language and cultural policy also decide translation policy, which in turn affects textual heritage, preservation, and dissemination" - tradução nossa.
}

TradTerm, São Paulo, v. 27, Setembro/2016, pp. 217-246

www.usp.br/tradterm

http://www.revistas.usp.br/tradterm/index 
RosA, G. M. - Tradução de quadrinhos: uma reflexão sobre a identidade cultural pelo viés do estereótipo judeu na linguagem dos quadrinhos

Brasil, a narrativa em quadrinhos favorece maior transparência no ato tradutório, pois seus textos híbridos, texto e imagem, a palavra mantém uma relação de interdependência com a ilustração na construção do sentido. Portanto, esse contexto suscitaria, a priori, estratégias de tradução que mantivessem a mesma relação dialógica entre texto e ilustração identificada no original. Assim, identificamos a possibilidade de limitações à liberdade do tradutor, despertando nosso interesse em investigar essas questões dentro de uma discussão que busca, justamente, questionar conceitos que se estabeleceram como certo e imutável, como a intolerância e discriminação contra minorias.

Acreditamos que a produção cultural de grupos étnicos, como os judeus, imprime na sua linguagem verbal ou imagética essas marcas herdadas e que compõem sua identidade cultural, por exemplo, léxicos do iídiche ou hebraico transliterado intercalados ao discurso da língua dominante, como o inglês americano. Quando essas marcas são preservadas no texto traduzido, reforça-se a existência do multiculturalismo em oposição à afirmação corrente de que países dominantes como os EUA são monolíngues. Como se vê, as políticas internas desse país, por exemplo, buscam tentativas de assimilação de culturas em uma homogeneização. Em consequência, apresentam-se falhas e somente destituem esses grupos minoritários de direitos e visibilidade dentro do país, principalmente com os grupos orientais, latinos e negros que moram nos bairros mais pobres e sobrevivem em subempregos.

Entretanto, no caso dos judeus nos EUA, lidamos com uma identidade que é composta pela etnia, religião e herança cultural dos países e respectivas línguas que cada grupo emigrou, especialmente no período da II Guerra Mundial. A grande parte dos imigrantes se estabeleceu em Nova York (GeNTZLeR 2008: 24; Rosenfeld 2012), e de acordo com Gentzler (op cit), é uma das poucas culturas que se manteve sólida e que mais conseguiu se preservar ao longo desse tempo. Dessa forma, precisamos atentar para o fato de que a identidade cultural como a vemos na representação do judeu, também traz 
RosA, G. M. - Tradução de quadrinhos: uma reflexão sobre a identidade cultural pelo viés do estereótipo judeu na linguagem dos quadrinhos

elementos diferentes entre si herdados de cada país onde essas pessoas viviam e se viram obrigadas a partir, além dos elementos comuns que as identificam propriamente na cultura judaica, precisando recomeçar nesse novo país, EUA, desde então.

Entendemos que esses elementos comuns, portanto, foram sendo compartilhados nesse momento de estabilização nos EUA através do convívio social e manutenção de suas tradições, mas também pela língua escrita, a preservação cultural, como no caso dos periódicos publicados e citados pelo autor (2008: 32$)^{7}$. Ainda, citamos também como exemplo da manutenção de traços identitários culturais do povo judeu as traduções da literatura universal conhecida na época para sua língua comum, o iídiche, e posteriormente para o hebraico na ocasião da criação do Estado de Israel (Cf. DelISLE 1995). Pensamos que por conta disso, a cidade de Nova York acaba por abrigar em sua multifacetada cultura uma enorme parcela de falantes do inglês que utilizam expressões do iídiche intercaladas com a língua dominante, preservando, assim, sua identidade cultural ${ }^{8}$.

Assim, essa incorporação na língua dominante, o inglês, de elementos linguísticos próprios provenientes do iídiche, uma língua considerada pertencente às comunidades judaicas, parece-nos uma tentativa de resistência e visibilidade de sua cultura dentro da cultura dominante: "a tradução nas Américas é menos algo que aconteça entre culturas separadas e distintas, e mais como aquilo que constitui essas culturas"9 (2008: 5).

\footnotetext{
${ }^{7}$ Gentzler cita alguns jornais escritos e publicados dentro da comunidade judaica, na língua hebraica transliterada e inglês (com grande uso de termos em iídiche) que circulavam na cidade de Nova York, no período pós-guerra.

${ }^{8}$ Como exemplo, podemos citar filmes mais autorais de americanos com ascendência judaica que retratam Nova York, como os escritos e dirigidos por Woody Allen, ou séries de TV de grande audiência nos EUA e exportadas para o resto do mundo, como Mad About You, Friends, Sex and the City, Curb your Enthusiasm, etc., sempre trazendo personagens judeus estereotipados ou não, mas que se utilizam de expressões judaicas, de origem iídiche, como oy, schmuck, shlepper, latke, Mazel tov, etc., em suas falas na língua inglesa.

9 "(...) translation in the Americas is less something that happens between separate and distinct cultures and more something that is constitutive of thoses cultures"
}

TradTerm, São Paulo, v. 27, Setembro/2016, pp. 217-246

www.usp.br/tradterm

http://www.revistas.usp.br/tradterm/index 
RosA, G. M. - Tradução de quadrinhos: uma reflexão sobre a identidade cultural pelo viés do estereótipo judeu na linguagem dos quadrinhos

\title{
O estereótipo e seu papel social enquanto
} representação

\author{
“Os estereótipos resistem ao tempo, \\ persistem como normas sobre o que fazer e \\ não fazer, dizer e não dizer, como agir e \\ como 'ser' no universo cultural em pauta. \\ São prisão e liberdade, exercem pressão e \\ proporcionam alívio (...)" \\ (HARKOT DE LA TAILLE 2013: 130).
}

Destacamos, nesta epígrafe, uma avaliação precisa sobre a importância em estudar os estereótipos nas diversas áreas de conhecimento, inclusive os Estudos da Tradução, por trazerem em sua formação e reprodução os mais variados impactos culturais que julgamos não ser possível escapar. Consequentemente, desperta-nos a necessidade de analisa-los, compreendêlos e até combater suas origens e propósitos quando partem de contextos hegemônicos, de intolerância e de dominância sobre o outro.

Com base na leitura de Amossy (2011) que parte da Análise do Discurso, várias questões relevantes acerca da conceituação do estereótipo nas ciências sociais foram despertadas, especialmente pela abordagem da psicologia social, demonstrando a sua relação, impacto e movimentação em grupos sociais.

Com maior destaque, traçamos brevemente, aqui, algumas considerações sobre a maneira com a qual o estereótipo é utilizado. Dentre tantos aspectos importantes e que merecem ser debatidos, ocorre-nos de pronto a necessidade de revisar a função do estereótipo nos grupos sociais pela práxis da leitura (de narrativas em quadrinhos, por exemplo), sua difusão e consequências, pois, não por acaso, trata-se precisamente da abordagem desta investigação: o estereótipo enquanto representação social. 
RosA, G. M. - Tradução de quadrinhos: uma reflexão sobre a identidade cultural pelo viés do estereótipo judeu na linguagem dos quadrinhos

Ao vermos em Amossy que a estereotipia pode ser nociva, mas também útil no processo de cognição na sociedade ${ }^{10}$, como rastrear ou definir esses dois percursos sem correr o risco de incorporar nosso próprio juízo de valor já que nós mesmos fazemos parte desse processo? Por exemplo, a autora defende que ambas vertentes surgem na investigação do estereótipo do ponto de vista empírico ${ }^{11}$ : a positiva e a negativa, isto é, uma corrente em que o estereótipo se encontra "no centro da reflexão sobre a identidade social" e seu papel cognitivo; e a vertente negativa em que é "vinculado às questões do preconceito e às tensões entre grupos sociais" (2011: 22). Penso não ser possível investigar o conceito de identidade cultural, que representa grupos sociais, de maneira desvinculada das tensões geradas não ocasionalmente quando grupos minoritários estão envolvidos.

Compreendemos, portanto, que o estereótipo apresenta uma função "utilitária" uma vez que é constituído de traços simplistas que facilitam a cognição, como defendido pela autora e, também, por Lippmann (1921). No entanto, questionamos a seguinte consideração, de que ainda que o estereótipo traga informação sobre o que representa, esta pode ser manipulada de acordo com os interesses dos grupos onde circula. Entendemos que o estereótipo traga um recorte, uma "face" ou "parte", de um todo muito mais complexo, e que nas circunstâncias em que se apresenta como, por exemplo, na leitura de uma narrativa em quadrinhos, seria impossível veicular esse todo, ou melhor, a complexidade da informação que ele representa. E, mais importante, corre-se o risco de que essa "parte eleita" para veicular a informação, muito provavelmente fora selecionada antecipadamente, talvez manipulada, e com propósitos definidos

\footnotetext{
${ }^{10}$ Cf. “Estereotipo y prejuicio”, pp. 38 e “Estereotipo y cognición” pp. 51 (Amossy 2011).

${ }^{11}$ Nesse ponto da discussão, a autora se refere à metodologia de questionários aplicados a grupos sociais específicos com perguntas acerca de estereótipos que se relacionam aos grupos que pertencem ao seu imaginário coletivo.
}

TradTerm, São Paulo, v. 27, Setembro/2016, pp. 217-246 www.usp.br/tradterm http://www.revistas.usp.br/tradterm/index 
RosA, G. M. - Tradução de quadrinhos: uma reflexão sobre a identidade cultural pelo viés do estereótipo judeu na linguagem dos quadrinhos

previamente, pois sempre "recortamos" a informação de algum modo e dificilmente enxergaremos fora do nosso olhar enviesado.

Dessa maneira, ambas vertentes, positiva e negativa, mesclam-se na investigação fazendo com que nosso olhar já venha carregado de "filtros", idiossincráticos ou coletivos, diante do nosso objeto. Como disse Lippmann (1921), "com frequência, não vemos primeiro e, então, definimos; nós primeiro definimos e, então, vemos"12. Ou seja, existe um filtro pelo qual interpretamos o mundo e isso ocorre a partir daquilo que já conhecemos (op cit).

Defendemos, portanto, que a postura a ser tomada pela sociedade, pelo tradutor e leitor, no caso da nossa investigação, seria pensar em como esse filtro se construiu, questioná-lo, refiná-lo por meio da reflexão e observação, pelo conhecimento de outras histórias e sobre outras coisas. Acreditamos não ser possível escapar dos "filtros", pois eventualmente cairemos em outros, já que não existe um local isento. Nos Estudos da Tradução, essas reflexões se tornam centrais, pois o viés de onde parte o olhar do tradutor, novamente, idiossincrático e coletivo, poderá legitimar ou desviar-se de estereótipos enraizados em uma determinada cultura.

Amossy (2011), ainda, tece considerações sobre os conjuntos de parâmetros que formam os estereótipos, as configurações sociais, associadas efetivamente às normas internas, endógenas, em que cada sociedade rege a si própria. Destacamos, com isso, que quando essas configurações partem e embasam-se verdadeiramente na Ética, mais análises positivas do que negativas do seu uso poderiam ser traçadas, pois o imaginário coletivo contribui enormemente para a construção e disseminação de estereótipos. Infelizmente, cada vez mais nos deparamos com um cenário nacional e internacional contrário a isso, onde o conceito de estereótipo é cunhado

\footnotetext{
12 "For the most part we do not first see, and then define, we define first and then see" tradução nossa. Lippman, W. (1921) "Stereotypes". Public Opinion. Capítulo 6 (pp. 2) Disponível em: www.gutenberg.org/cache/epub/6456/pg6456.html. Acesso em: ago. 2013.
} 
RosA, G. M. - Tradução de quadrinhos: uma reflexão sobre a identidade cultural pelo viés do estereótipo judeu na linguagem dos quadrinhos

praticamente como um sinônimo para algo negativo. Essa observação tem como base a leitura do cenário ficcional (narrativas de obras literárias, séries de TV, novelas e, também, narrativas em quadrinhos), como também do cenário não-ficcional, principalmente, os meios midiáticos (jornais impressos, digitais ou televisionados, e revistas de comportamento ou política). No âmbito das pesquisas acadêmicas que investigam como se "constrói discursivamente a intolerância”, vários autores (BARROS 2011, LEITE 2008, FIORIN 1988) alertam para procedimentos e estratégias usados na ruptura de "contratos sociais" entre enunciador e enunciatário resultando em preconceitos linguísticos: “(...) no caso dos discursos intolerantes, há apenas 'estabilização' temática, pois há discursos intolerantes em diferentes esferas de atividades (política, religiosa, familiar), de gêneros diversos (notícias, sermões, bate-papo, etc.) e de tipos diferentes (narrativo, descritivo, etc.)". (BARROS 2011: 02).

Segundo Amossy (2011: 131), é possível esquematizar essa análise sobre o funcionamento das normas endógenas a partir dos seguintes vieses: o viés cognitivo - o estereótipo étnico ou racial em si; o viés afetivo - o preconceito ou hostilidade em relação a estereótipos; e o viés pragmático ou comportamental - "a discriminação ou o desfavorecer alguém devido ao seu pertencimento a um grupo concebido e tratado estereotipicamente com valoração negativa" (op cit). Ao pensarmos no uso e leitura do estereótipo na literatura ou outra linguagem narrativa do âmbito ficcional, destacamos na investigação desta pesquisa o segundo e terceiro viés, pois dialoga diretamente com o discurso da intolerância e a formação de identidades culturais.

Trazendo essa discussão para o âmbito dos Estudos da Tradução, como o corpus selecionado para a análise, o estereótipo utilizado enquanto representação suscita ainda mais o nosso interesse de investigação, pois se trata da leitura e interpretação do tradutor de espaços divergentes, outros países e outras línguas. Lippmann (1921) também chama a atenção para a 
RosA, G. M. - Tradução de quadrinhos: uma reflexão sobre a identidade cultural pelo viés do estereótipo judeu na linguagem dos quadrinhos

dificuldade de precisão na identificação ou no julgamento de algo que passa a ser distante do nosso olhar. Ele descreve, nesse exemplo simples, a credibilidade frágil de testemunhas para processos judiciais, demonstrando a subjetividade presente em todas as "transmissões de mensagens". ${ }^{13}$ Ele ainda diz que os "fatos que vemos dependem de onde estamos posicionados e dos hábitos do nosso olhar" (op cit).

Quando aproximamos esse conceito à tradução, ou melhor, a leitura que um tradutor pode fazer de uma cultura que não é a sua, independentemente do grau de distância da sua própria, parece-nos uma questão ainda mais complexa. As informações, desse modo, que este primeiro leitor, leitor-tradutor, teria acesso, perpassariam com mais facilidade pelo estereótipo, devido às limitações naturais da informação que chegou até ele, do lugar e das circunstâncias com que ele entraria em contato. Aqui, estamos nos referindo também ao imaginário coletivo, que perpassam pelas ideologias incorporadas no desenvolvimento dos indivíduos e, principalmente, na adesão dos estereótipos. Segundo Harkot de La Taille (2013: 134), "o estereótipo resulta em generalização" e quando pensamos na variedade de características negativas que podem ser transmitidas e/ou legitimadas pelo recorte, entendemos aqui a necessidade de aprofundar a investigação nos impactos resultantes na comunidade leitora.

\footnotetext{
${ }^{13}$ Nesse exemplo, o autor cita um estudo feito com testemunhas oculares e seus depoimentos no Tribunal de Justiça. Ele afirma que os resultados demonstraram que a credibilidade varia de acordo com os grupos de testemunhas, os grupos de eventos e o tipo de percepção. Por exemplo, "nossa audição é imperfeita e arbitrária quando precisa julgar a fonte e direção de um som ou compreender palavras de outras pessoas, podendo ser supridas pela testemunha com boa fé" (op cit pp. 1).
}

TradTerm, São Paulo, v. 27, Setembro/2016, pp. 217-246

www.usp.br/tradterm

http://www.revistas.usp.br/tradterm/index 
RosA, G. M. - Tradução de quadrinhos: uma reflexão sobre a identidade cultural pelo viés do estereótipo judeu na linguagem dos quadrinhos

\section{Um estudo de caso: The Story of the Jews - a 4,000-Year Adventure (2001); A História dos Judeus - uma Aventura de 4.000 anos (2009)}

A História dos Judeus é um livro que narra, na linguagem dos quadrinhos, a trajetória do povo judeu, com mapas e representações dos personagens em cada momento histórico destacado. Com seus capítulos divididos em três grandes temas - "Recebendo a Mensagem”, “O Povo de um Outro Lugar” e “Viagem no Tempo e no Espaço” - há uma divisão também em subcapítulos separados por datas que marcam transições de um momento histórico para outro.

O livro The Story of the Jews - a 4,000-Year Adventure, de Stan Mack, teve sua primeira publicação em 2001, pela editora americana Jewish Lights Publishing, estando em sua sétima edição (2011) que compõe nosso corpus da pesquisa. Sua tradução (2009) feita por Maria Beatriz de Medina também foi publicada por uma editora especializada no catálogo de títulos judaicos, o selo Povo do Livro que pertence à Via Lettera. Esta é uma das editoras pioneiras na publicação de livros na linguagem em quadrinhos e a tradução já se encontra na segunda edição (2011), sendo esta última a selecionada para o corpus. Já o selo da Via Lettera, Povo do Livro, oferece um catálogo exclusivamente da literatura iídiche, com apenas dois livros em quadrinhos, este e As Aventuras de Rabbi Jacob, de Steve Sheikin, cujo original também pertence à editora americana.

Sobre os elementos paratextuais, vejamos as capas dos livros, original e tradução: 
RosA, G. M. - Tradução de quadrinhos: uma reflexão sobre a identidade cultural pelo viés do estereótipo judeu na linguagem dos quadrinhos
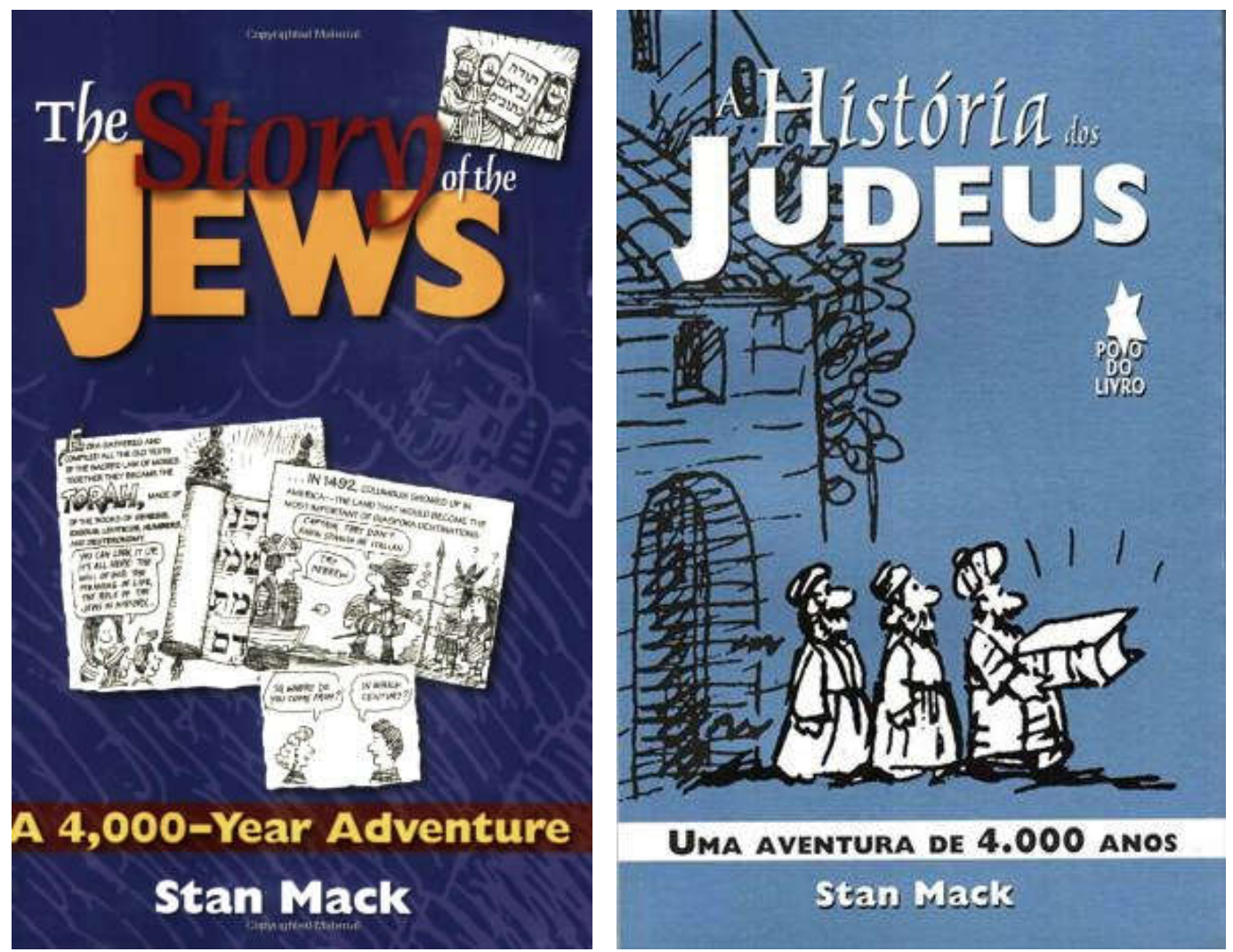

UMA AVENTURA DE 4.000 ANOS

Stan Mack

Fig. (1) e (2): Capas de The Story of the Jews (2001) e História dos Judeus (2009).

Como se vê, a capa do livro original, em inglês, é azul escura, seu título apresenta três cores (branco, vermelho e amarelo), e as palavras destacadas são "story" em vemelho e “Jews" em amarelo, esta última maior do que o restante. Vemos traços em lilás claro que compõem o fundo da capa e que permitem distinguir, muito sutilmente, uma mão segurando um livro aberto. Temos, também, quatro quadrinhos retirados do conteúdo do livro: três estão agrupados no centro e um foi colocado no topo da capa, ao lado do título. Nos quadrinhos agrupados, vemos no primeiro a apresentação da Torá, símbolo maior da religião judaica, com textos em hebraico não transliterado; no segundo, um pulo no tempo para o século 15, com a ilustração representando índios e a chegada de Colombo na América, continente que recebeu a maior parte dos imigrantes judeus da atualidade; no terceiro, mais um salto na representação para a época presente: a imagem de um casal de pessoas 
RosA, G. M. - Tradução de quadrinhos: uma reflexão sobre a identidade cultural pelo viés do estereótipo judeu na linguagem dos quadrinhos

conversando, uma alusão possível de que se trata de duas pessoas de ascendência judaica, quando a mulher diz “Então, de onde você vem?"14 e o homem responde “Em qual século?” 15 , ressaltando não só o deslocamento dos povos judaicos pelo mundo, como sua existência ao longo de quatro séculos. Abaixo dos quadrinhos, temos o subtítulo (A 4,000-Year Adventure) destacado numa faixa vermelha com as letras em amarelo e, na sequência, o nome do autor. No quadrinho isolado, temos na ilustração três homens com trajes antigos (túnicas e turbantes) segurando um livro, novamente com textos em hebraico.

A capa do livro traduzido, diferentemente do original, apresenta apenas cores mais sutis: azul, branca e preta. A capa é azul clara, com traços pretos que esboçam a imagem de uma casa de onde parecem ter saído os três homens com trajes antigos (chapéu, turbante e túnicas amarradas na cintura) retratados em fila indiana, o primeiro deles com um livro na mão. Essa cena que vemos também foi retirada do conteúdo, trata-se de um único quadrinho ampliado, pois abrange a totalidade da capa. A ilustração deles é apenas nas cores branca e preta, como todo o conteúdo do livro, e também o título. A palavra “judeus” também está destacada e com tamanho maior do que as demais, inclusive com a primeira letra em caixa alta, como a palavra inglesa, discordando, assim, da prática de grafia do português ${ }^{16}$. Entre a ilustração e o nome do autor, também vemos o subtítulo do livro (Uma aventura de 4.000 anos) com a fonte na cor preta dentro de uma faixa branca. Por último, temos o selo da editora à direita, próximo ao título, também na cor branca, composto pelo nome, Povo do Livro, e uma estrela de seis pontas em que a

\footnotetext{
14 "So, where do you come from?" (minha tradução) In: MACK 2001: capa

15 "In which century?" (idem)

${ }^{16}$ A norma na língua inglesa para nacionalidades (adjetivos pátrios) e outros substantivos correlacionados como o caso de judeu (aquele que pertence à Judeia), diz que devem ser grafados com a primeira letra maiúscula. Já a língua portuguesa prescreve que enquanto os substantivos referentes às nações devam seguir a mesma regra ortográfica, o caso das nacionalidades não se aplica, isto é, estas devem ser grafadas em letra minúscula.
}

TradTerm, São Paulo, v. 27, Setembro/2016, pp. 217-246

www.usp.br/tradterm

http://www.revistas.usp.br/tradterm/index 
RosA, G. M. - Tradução de quadrinhos: uma reflexão sobre a identidade cultural pelo viés do estereótipo judeu na linguagem dos quadrinhos

inferior forma a letra "v" de "povo". Embora não seja a representação ilustrativa mais comum da Estrela de Davi ${ }^{17}$, outro símbolo importante da religião judaica, dificilmente o leitor não associaria uma à outra, pois o conceito "Povo do Livro", nome do selo editorial, é atribuído ao judaísmo religioso ${ }^{18}$.

Contudo, apesar de todas as diferenças apontadas, a composição do livro traduzido segue o padrão do original com a mesma sequência: folha de rosto e dedicatória; agradecimentos; sumário; introdução; índice remissivo, além da divisão exata dos títulos de capítulo, subtítulos e mapas a cada mudança de capítulo.

É interessante constatar que ambos os livros trazem propaganda de publicações de suas editoras nas últimas páginas, logo após o índice remissivo, sendo 17 páginas no livro original e apenas duas na tradução. Por fim, o livro original utiliza a segunda capa, interior da capa, para apresentar a história. Este texto é retirado da introdução, com uma sinalização própria para isto ("from the Introduction"), além de mais dois releases de escritores sobre o livro. Já a edição traduzida faz o mesmo, porém em outro espaço do livro, nas orelhas adjacentes à capa e contracapa. Vemos que a edição original se utiliza de todos os espaços do livro, pois na terceira capa, interior da contracapa, temos a breve biografia do autor. Esse espaço também é utilizado para anunciar as publicações em quadrinhos de outro autor. Para estas informações, a minibiografia de Mack, a edição traduzida se utiliza da orelha da contracapa.

\footnotetext{
${ }^{17}$ A Estrela de Davi, como se sabe, além das seis pontas, é "vazada", ou melhor, formada por dois triângulos sobrepostos.

${ }^{18}$ Os judeus religiosos são conhecidos em ter na sua bíblia, o livro Torá, a concentração de todo o conhecimento divino, razão pela qual se acredita que o povo judeu tenha sobrevivido durante tantos séculos.
} 
RosA, G. M. - Tradução de quadrinhos: uma reflexão sobre a identidade cultural pelo viés do estereótipo judeu na linguagem dos quadrinhos

Consideramos, não obstante, observar nesta investigação a Introduction/Introdução ${ }^{19}$ escrita pelo autor enquanto elemento paratextual central, pois nela identificamos uma carta em primeira pessoa direcionada ao leitor. Além de apresentar o conteúdo do livro, o autor também descreve como o projeto da obra surgiu, as motivações iniciais e um pouco do processo de criação, como a necessidade de pesquisa, e suas considerações sobre o resultado final. Além disso, neste prefácio, Mack chama a atenção para a linguagem que o leitor irá encontrar e que, segundo ele, é diferenciada, pois não se trata de um livro ilustrado e tampouco de quadrinhos, mas que traria, na verdade, a "concisão da charge política"20.

$\mathrm{Na}$ introdução, o autor, que é um premiado cartunista ${ }^{21}$, explica como dá essa forma à estrutura do todo, e vemos que não há personagens específicos, com nome e histórias particulares que vamos acompanhando, mas sim uma sucessão de personagens que representam o coletivo da época que são apresentados.

\section{O mapeamento histórico-cultural de um povo na linguagem dos quadrinhos enquanto representação da identidade cultural}

Destacamos em nossa leitura do conteúdo e elementos paratextuais de A História dos Judeus, de Stan Mack, neste caso, a Introdução ou Prefácio,

\footnotetext{
${ }^{19}$ MACK 2001: xiii; MACK 2009: 09.

20 "the conciseness of a political cartoon" In: 2001; 2009.

${ }^{21} \mathrm{Na}$ orelha do livro, um dos elementos paratextuais analisados, temos a breve biografia do autor e vemos que Mack trabalhou como cartunista por mais de vinte anos, além de ilustrador de livros infantis e escritor de ficção.
}

TradTerm, São Paulo, v. 27, Setembro/2016, pp. 217-246

www.usp.br/tradterm

http://www.revistas.usp.br/tradterm/index 
RosA, G. M. - Tradução de quadrinhos: uma reflexão sobre a identidade cultural pelo viés do estereótipo judeu na linguagem dos quadrinhos

que o viés condutor dessa narrativa é o jornalístico, pois acompanhamos a descrição de momentos históricos que, segundo o autor, foram baseados em extensa pesquisa de fatos registrados sobre a trajetória dos judeus pelo mundo $^{22}$ em todas as épocas representadas no livro. Além disso, vemos também que a ilustração que acompanha o texto (Fig 3 e 4) traz o humor característico das charges jornalísticas, não apenas nos traços, mas também na presença de ironia.

Estruturalmente, a charge tem na caricatura a presença de elementos para expressão direta de sua crítica. Os traços hiperbólicos, marcados por um exagero intencional, são os responsáveis pela deformação simbólica. No entanto, o excesso proposital não impede que o leitor reconheça ou identifique a personagem representada. A argumentação chárgica apresenta-se, então, como um processo que deriva de marcações ideológicas bem estabelecidas: é o humor que permite ao chargista refletir ou refratar a realidade (OLIVEIRA 2013: 185).

Muitos dos textos, os recordatórios, que vão descrevendo o comportamento e o cotidiano do judeu ao longo da História, são acompanhados de comentários bem-humorados sobre aquilo que está sendo relatado por personagens famosos ou anônimos, tal como veríamos em uma charge.

No exemplo que se segue (Figuras 3 e 4), trata-se do início do livro, no período histórico que retrata a trajetória do patriarca hebreu Abraão e sua esposa Sara, chegando à terra prometida, Canaã.

\footnotetext{
22 Por exemplo, ao consultar as fontes primárias como o Velho Testamento, cujo livro chamado Pentateuco é justamente a Torá, a Bíblia judaica, deparamo-nos com inúmeras narrativas que Mack retrata em seu livro, como as ações dos profetas, dos juízes das tribos de Israel, dos reis hebreus e seus sucessores, etc.
} 
RoSA, G. M. - Tradução de quadrinhos: uma reflexão sobre a identidade cultural pelo viés do estereótipo judeu na linguagem dos quadrinhos

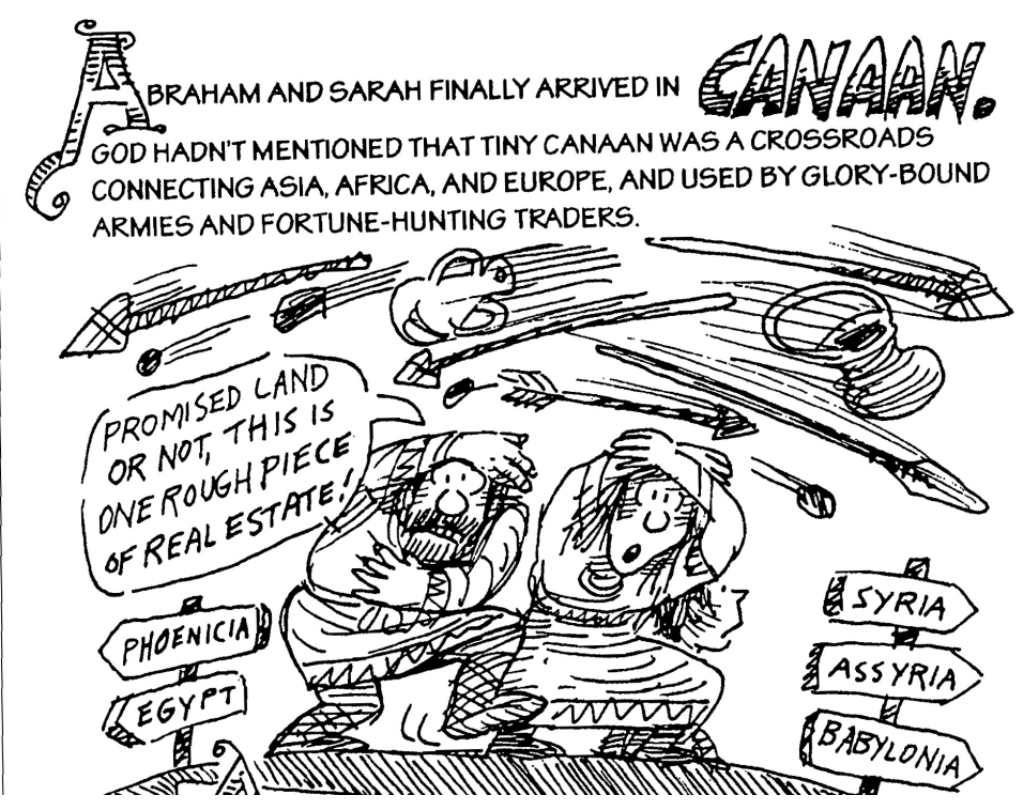

Fig. (3): The Story of the Jews (2001: 11)

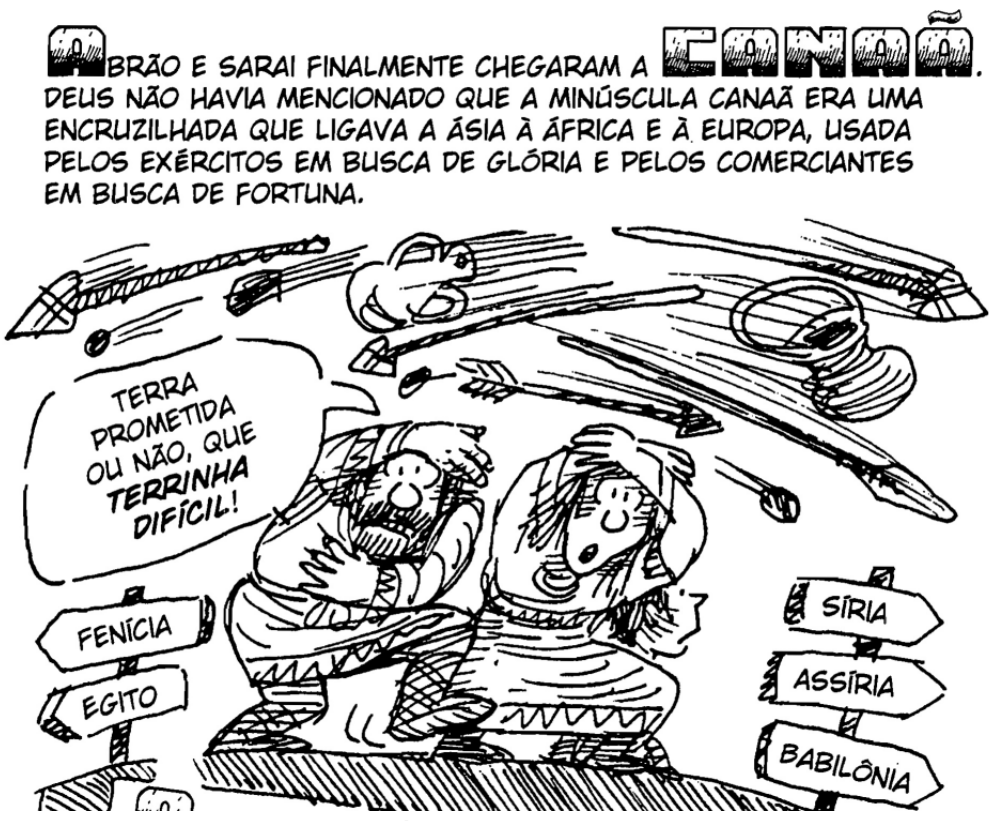

Fig. (4): A História dos Judeus (2011: 21)

Nesse exemplo, vemos uma representação humorística de uma cena bíblica que entrelaça tema religioso e antigo a expressões verbais 
RoSA, G. M. - Tradução de quadrinhos: uma reflexão sobre a identidade cultural pelo viés do estereótipo judeu na linguagem dos quadrinhos

contemporâneas com efeitos de humor, como "one rough piece of real state" que fora traduzido para "terrinha difícil".

Vejamos o próximo exemplo:

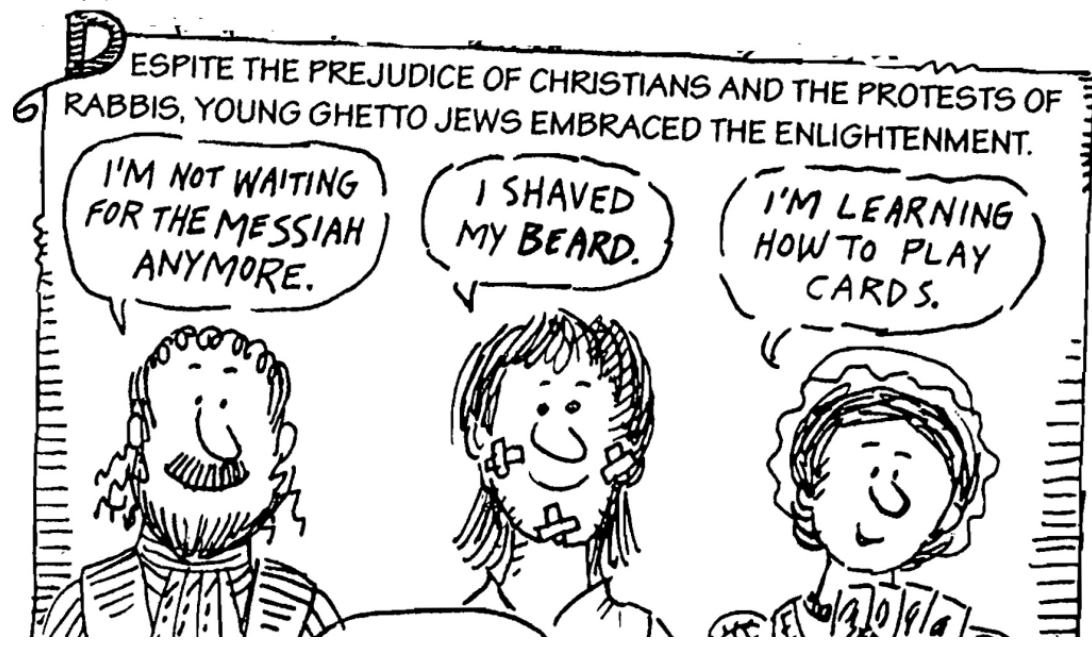

Fig. (5): Story of the Jews (2001:182)

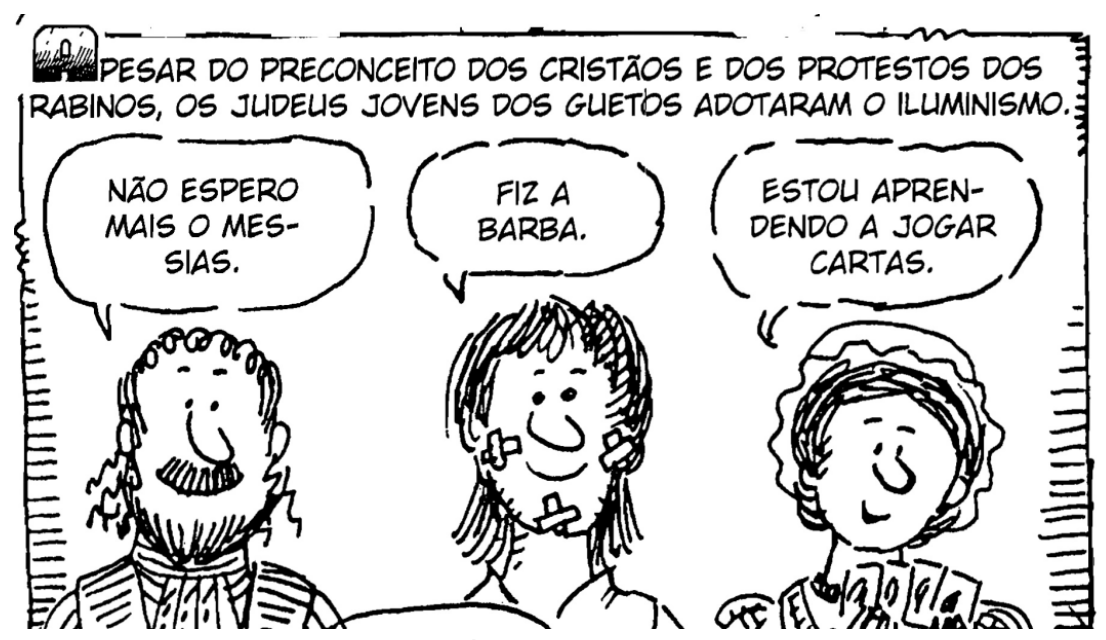

Fig. (6): A História dos Judeus (2011: 192)

Neste exemplo, recortamos um quadrinho pertencente ao contexto que representa os judeus asquenazes na Europa do século 18, no lluminismo. Vemos que eles são retratados numa Alemanha mais aberta a incorporá-los à sociedade. Mas isso, com a condição de que deixassem sua própria cultura de lado como, por exemplo, modificar seus nomes para aqueles mais similares à 
RosA, G. M. - Tradução de quadrinhos: uma reflexão sobre a identidade cultural pelo viés do estereótipo judeu na linguagem dos quadrinhos

língua alemã, além da adaptação de hábitos e costumes, como a aparência e crenças religiosas. Como citado anteriormente, identificamos nesse exemplo o estilo do autor em descrever uma época com seus fatos históricos, mas colocando, também, "personagens" que comentam os episódios com opiniões bem humoradas: "Não espero mais o Messias", "Fiz a barba", "Estou aprendendo a jogar cartas" (2009: 172).

Além disso, o autor declara na introdução ou prefácio (MACK 2001: xiii; MACK 2009: 09) do livro que seu conteúdo buscou apresentar fidelidade à História, isto é, que houve uma preocupação sua em representar aquilo que ele pesquisou em um vasto material. Aqui, revela-se o ponto de vista do autor que apresenta ao leitor, no prefácio, que ele buscou representar o conhecimento apreendido em suas pesquisas de maneira simplificada, em suas próprias palavras, para que o resultado final despertasse no leitor a procura de um aprofundamento do estudo (op cit).

A introdução, a nosso ver, apresenta um tom epistolar, isto é, identificamo-la como uma "carta" direcionada ao leitor judeu. Ao reler a introdução, podemos nos deter nos marcadores linguísticos que deixam claro que o destinatário do autor não é qualquer leitor que possa se deparar com o livro, e sim um leitor judeu como ele. No início do texto, não percebemos que se trata exclusivamente de um leitor peculiar, pois ele diz, por exemplo, "Caminharemos com os profetas, que nos indicaram a crença de um só Deus" e "Esta é a história do 'Povo do Livro', que nos ensina que tudo tem um objetivo e um significado" (grifo nosso) ${ }^{23}$. De fato, sabemos que a religião judaica apresentou para o mundo o monoteísmo, além de fazer parte da formação judaico-cristã do Ocidente. Além disso, poderia significar também que, através da história, a cultura judaica contribuiu muito com as culturas que se seguiram, estando todos nós incluídos nesse pronome.

\footnotetext{
23 "We will walk with the Prophets, who pointed us toward a belief in one God"; "This is the story of the 'People of the Book', who have taught us that there is purpose and meaning in everything". (grifos nossos): In: 2001; 2009; pp. xiii-xiv, 10-11.
}

TradTerm, São Paulo, v. 27, Setembro/2016, pp. 217-246 www.usp.br/tradterm

http://www.revistas.usp.br/tradterm/index 
RosA, G. M. - Tradução de quadrinhos: uma reflexão sobre a identidade cultural pelo viés do estereótipo judeu na linguagem dos quadrinhos

Entretanto, em seguida, ele diz: “Para os que quiserem sentir que fazem parte de uma comunidade, eis um exame de quem somos, de como chegamos até aqui e do laço histórico que liga todos os judeus" (grifo nosso) ${ }^{24}$; e no final do texto, ele encerra com "como o povo que somos". É importante lembrar que ambas as edições, original e tradução, são publicadas por editoras especializadas em literatura judaica, a americana Jewish Lights Publishing e a brasileira pelo selo Povo do Livro, respectivamente e, dessa forma, entendemos ser esta a razão principal que levou o autor a direcionar sua obra a um leitor específico.

Entretanto, apesar de a introdução ser direcionada ao leitor judeu, pensamos que as editoras trabalharam para todos os tipos de leitores, pois na folha de rosto do livro original, há uma frase que faz parte do logo da Jewish Lights Publishing e diz "For People of All Faiths, All Backgrounds" (Para pessoas de todas as crenças, de todas as heranças culturais - tradução nossa). Partimos do princípio, portanto, de que uma editora que tem esta frase como lema de suas publicações se direciona, efetivamente, para todo tipo de leitor, abrangendo o seu alcance e não o excluindo.

Contudo, também não podemos desconsiderar que o leitor que esteve em contato com os livros passará pela introdução, mesmo que não faça parte dessa comunidade leitora e, portanto, receberá o impacto que esta chave de leitura traz e que pode afetar sua interpretação do estereótipo do judeu como, por exemplo, pelo viés da exclusão, da comunidade fechada. Um aspecto que se atribui com frequência ao estereótipo do judeu é este pertencer e manter-se em uma comunidade mais fechada, distante dos não judeus. Pode-se justificá-lo pela imposição de isolamento, ao longo da história, como as autoridades europeias e russas que os segregaram em guetos nos séculos 16 e 17, sem poderem conviver com o restante da sociedade e,

\footnotetext{
24 "For all those with a desire to connect, this is an exploration of who we are, how we got here, and the historical bond linking all Jews"; “(...) like the people we are" (grifos nossos). Idem.
} 
RoSA, G. M. - Tradução de quadrinhos: uma reflexão sobre a identidade cultural pelo viés do estereótipo judeu na linguagem dos quadrinhos

desse modo, teriam se organizado nos mais diferentes países com um perfil mais discreto e isolado dos que não pertencem à comunidade.

Passando, agora, para outro aspecto que nos chamou a atenção na leitura desse livro. Aqui, há a presença da palavra "história" na tradução do título cujo equivalente ad hoc não existe no original. Onde se lê "The Story of the Jews", temos a tradução "A História dos Judeus". Em nossa leitura e construção do significado, a opção lexical do tradutor se deu, principalmente, pela inexistência do item lexical "Estória" na língua portuguesa contemporânea. Sendo assim, torna-se completamente aceitável e corrente o uso de "história" para se tratar de ficção e não-ficção em nossa cultura. No entanto, no texto original, ambos os itens lexicais "story" e "History" trazem acepções divergentes e que precisam ser levadas em consideração. Como se sabe, "History" 25 com a letra inicial "H" em caixa alta se refere unicamente a fatos históricos. Porém, quando usada a letra "h" minúscula, pode se referir a histórias de pessoas, ou narração de eventos do passado, contanto que verídicas, isto é, não-ficcionais. o contrário ocorre com o uso de "story". Segundo o dicionário Michaelis, praticamente todas as acepções inferem algum tipo de traço ficcional ou, pelo menos, fatos não inteiramente verídicos: "1 conto, relato, narrativa, crônica. 2 novela, lenda, história, fábula, romance, conto, anedota. 3 Coloq. mentira. 4 enredo de novela ou de peça teatral. 5 boato". Destacamos, aqui, a possibilidade do autor, Mack, sugerir na escolha do item lexical "Story" no lugar de "History", justamente uma narrativa de fatos históricos, mas representados à sua maneira, ou seja, de acordo com a sua interpretação desses mesmo fatos. Assim, permitiu-se criar diálogos bem-humorados e, consequentemente, ficcionais, nas falas de personagens e fatos da história do povo judeu. Na tradução, contudo, perde-

${ }^{25}$ History: 1. the study of past events; 2 . events of the past; 3. past events that relate to a particular subject, place, organization, etc. Disponível em: www.merriamwebster.com/dictionary/history (1. o estudo de eventos passados; 2 . eventos do passado; 3. eventos passados relacionados a pessoas, lugares, organizações, etc. - tradução nossa).

TradTerm, São Paulo, v. 27, Setembro/2016, pp. 217-246

www.usp.br/tradterm

http://www.revistas.usp.br/tradterm/index 
RosA, G. M. - Tradução de quadrinhos: uma reflexão sobre a identidade cultural pelo viés do estereótipo judeu na linguagem dos quadrinhos

se esse significado e essa revelação do ponto de vista do autor ao optar-se por "História" como equivalente.

Por fim, identificamos também um aspecto revelador da tradução deste livro, especificamente, que dialoga com as linhas editoriais que ambos, o original e a tradução, compartilham: a temática judaica. Constatamos uma tendência para uma tradução "visível” (VENUTI 1995), isto é, com a presença muito destacada do recurso de acréscimos, reformulações às vezes um pouco distantes do sentido, e amplo uso da explicitação para quase todos os termos da cultura judaica. A categoria que mais evidencia essa observação relacionase com a presença da língua hebraica (transliterada) e o iídiche.

Ao mesmo tempo em que a introdução do livro se dirige a um leitor específico, judeu e, portanto, sugere que este leitor compartilha a identidade e conhecimento do autor, vemos uma grande quantidade de exemplos que trazem termos na língua hebraica transliterada ou iídiche, acompanhados de explicação na língua inglesa, inferindo que seu leitor não estaria tão familiarizado com esses termos.

Por outro lado, apesar de esse recurso facilitar o trabalho da tradutora, vemos, também, que há muita "interferência" na tradução deste livro, no sentido de parecer existir uma forma peculiar de apresentar esses significados na língua portuguesa, tamanha a quantidade de escolhas que despertaram a nossa atenção. Notamos essa peculiaridade, especialmente, naquelas cuja origem dos itens lexicais se encontra no iídiche, revelando-se na tradução essa tendência, isto é, rejeitou-se apresentar os termos tal como se conhece na língua original (hebraico ou iídiche), optando-se por apresentá-los na maneira que o suposto "judeu brasileiro" os conhece. Por exemplo, a palavra "Adonai" (pp. 20, 30, In: 2001, 2009) que, em nossa pesquisa sobre este item lexical, vemos que o seu equivalente na língua portuguesa seria o mesmo. No entanto, a tradutora optou por "A-d-onai”. Na busca desta variante, vemos que alguns sites especializados trazem esta opção da tradutora, com as 
RosA, G. M. - Tradução de quadrinhos: uma reflexão sobre a identidade cultural pelo viés do estereótipo judeu na linguagem dos quadrinhos

sílabas separadas, mas a maioria de exemplos buscados, seja na língua portuguesa, como na língua inglesa, apresentam a palavra como no original.

Observamos, também, amplo uso do recurso de explicitação para os termos específicos traduzidos da tradição judaica, até mesmo na Introdução do livro, quando lemos que o autor se reporta ao leitor “judeu”. Esse fato sugere que o público alvo desta tradução não são judeus, pois esta se mostra com uma necessidade de explicar os significados de todo esse universo, até mesmo de termos que já fazem parte da cultura geral, conhecidos pela comunidade não-judaica como, por exemplo, Bar Mitzvah, Yom Kippur e Chanukah (pp. 261, 271; 260, 270; 257, 267, respectivamente). Além de optar pela mudança ortográfica de todos para a versão portuguesa (Bar Mitsvá, lom Kipur e Chanucá), a tradutora também acredita que existe a necessidade de explicar seus significados ao leitor.

Outros exemplos flagrantes nesse sentido são os casos em que o autor se utiliza de um termo da língua inglesa, "gentiles" e a tradutora prefere usar um termo de origem hebraica, "goim”, e não seu equivalente literal, “gentios", necessitando, mais uma vez, do uso da explicitação para dar conta do significado para o leitor. Por fim, outro caso interessante a ser mencionado encontra-se na Introdução, que vem acrescida de três notas de rodapé, sendo que para a explicação de uma delas é justamente uma palavra em português: sinagoga. É, de fato, uma indicação de que o livro é direcionado para leigos, e não o contrário como o conteúdo do texto infere.

Finalmente, identificamos que os termos na língua hebraica (transliterada) e iídiche percorrem mais o contexto não religioso do que as menções referentes à religião, diferente do que supúnhamos, já que o uso de termos de uma língua tão antiga, naturalmente, manter-se-ia viva pela existência da religião. Essa constatação é relevante para a investigação da identidade judaica, pois indica que esses termos utilizados em situações cotidianas demonstram uma relação que une falantes de diferentes épocas, independente da língua, pois como mencionado anteriormente, o livro traz 
RoSA, G. M. - Tradução de quadrinhos: uma reflexão sobre a identidade cultural pelo viés do estereótipo judeu na linguagem dos quadrinhos

um panorama histórico de diferentes regiões e épocas da trajetória do povo judeu.

Com isso, destacamos a relevância em dar continuidade a essa investigação em outros trabalhos, dadas as potencialidades encontradas nessa breve apresentação e análise. Como vimos, a representação da identidade cultural na linguagem dos quadrinhos traz diversas nuances na relação entre texto e imagem e julgamos pertinente discuti-las no âmbito dos Estudos da Tradução, visto o seu alcance além das fronteiras em que essas narrativas foram criadas. Nesta obra, em particular, vimos que o uso de personagens mais generalizados, isto é, sem o acompanhamento de suas histórias individuais, pelo contrário, usados como representações gerais de momentos históricos, caracteriza a importância da obra, pois the atribui o caráter de charge jornalística. Portanto, para futuros trabalhos, identificamos a necessidade de investigar os diálogos entre os personagens retratados que comentam cada recordatório e, consequentemente, cada momento histórico representado da trajetória do povo judeu. Os recordatórios, aqui, são os textos explicativos dentro do quadrinho e que trazem as informações históricas baseadas na pesquisa do autor. Assim, vislumbramos uma abordagem da pesquisa que reunirá mais dados dessa representação da identidade cultural e o modo como fora resgatada no texto traduzido.

\section{Referências bibliográficas}

Amossy, R.; Herschberg-Pierrot, A. Stéréotypes et Clichés: Langue, Discours et Société. Paris: Armand Colin, 2011. - Estereotipagem e a construção de uma imagem de si. In: Imagens de si no Discurso: a construção do ethos. São Paulo: Contexto, 2005 
RoSA, G. M. - Tradução de quadrinhos: uma reflexão sobre a identidade cultural pelo viés do estereótipo judeu na linguagem dos quadrinhos

BARROS, D. L. P. A construção discursiva dos discursos intolerante. In: Diana Luz Pessoa de Barros (Org.). Preconceito e intolerância. reflexões linguísticodiscursivas. 1ed. São Paulo: Editora Mackenzie, pp. 257-276, 2011, v. 1. In: http://diversitas.fflch.usp.br/files/Texto\%20Profa.\%20Diana\%20Luz\%20Pessoa \%20de\%20Barros\%20(1).pdf

CAGNIN, A. L. Os quadrinhos. São Paulo: Ática, 1975.

DelisLe, J; WoodsWorth, J. Os tradutores na história. Trad. Sergio Bath. São Paulo: Ática, 1995.

Eco, U. Leitura de 'Steve Canyion' e 0 mundo de Minduim. In: Apocalípticos e Integrados. São Paulo: Perspectiva, 2004.

EISNER, W. Quadrinhos e Arte Sequencial: princípios e práticas do lendário cartunista. Trad. Luis Carlos Borges, Alexandre Boide. $4^{\text {a }}$ ed. São Paulo: WMF Martins Fontes, 2010.

FIORIN, J. L. Linguagem e ideologia. São Paulo: Ática, 1988.

GeNTZLER, E. Translation and Identity in the Americas: New Directions in Translation Theory, London and New York, Routledge, 2008

HARKOT-DE-LA-TAILlE, E. Entre sapos e princesas, corações e mentes. In: Sentir, saber, tornar-se: estudo semiótico do percurso entre o sensório e a identidade narrativa. São Paulo, 2013, Tese de Livre-Docência.

- Crise Identitária: Imagens de $\mathrm{Si}$ do Agente Penitenciário, em Entrevistas sobre o Disciplinar. Discurso, Teoría y Análisis, Cidade do México, v. 27, n. 1, p. 85-119, 2007.

LEITE, M. Q. Intolerância e preconceito na linguagem. São Paulo: Contexto, 2008.

LIPPMANN, W. "Stereotypes" Public Opinion. The Project Gutenberg EBook of Public Opinion, by Walter Lippmann. 2004. Disponível em: www.gutenberg.org/ebooks/6456. Acesso em: abr. 2013.

. Opinião Pública. Tradução e Prefácio: Jacques

A. Wainberg. Editora Vozes: Petrópolis, 2008

MACK, S. The story of the Jews: a 4,000-year adventure. Woodstock: Jewish Lights Publishing, 2001.

- A história dos judeus: uma aventura de 4.000 anos. Trad. Maria

Beatriz de Medina. São Paulo: Via Lettera, 2009.

Oliveira, E.; SANTOS, R. de. P.; Borges, R. da S. Identidades e representações nos sistemas midiáticos (in)formativos: a charge a construção da imagem do Outro. Rumores, n. 14, v. 7, jul.-dez 2013. Disponível em: www.revistas.usp.br/Rumores/article/viewFile/69438/pdf_4 
RosA, G. M. - Tradução de quadrinhos: uma reflexão sobre a identidade cultural pelo viés do estereótipo judeu na linguagem dos quadrinhos

Ramos, P. Histórias em quadrinhos: gênero ou hipergênero? Comics: genre or hypergenre?. Estudos Linguísticos, São Paulo, 38 (3), pp. 355-367, set.-dez. Universidade Metodista de São Paulo (UMESP), 2009a. Disponível em: www.gel.org.br/estudoslinguisticos/volumes/38/EL_V38N3_28.pdf. . A leitura dos quadrinhos. São Paulo: Contexto, 2009b. - Tiras cômicas e piadas: duas leituras, um efeito de humor. Tese de Doutorado em Letras. São Paulo: Universidade de São Paulo, 2007.

Ramos, P; FIgUeIRA, D. Graphic Novel, Narrativa Gráfica ou Romance gráfico? Terminologias distintas para um mesmo rótulo, 2011. Disponível em: www.gelbc.com.br/pdf_jornada_2011/paulo_ramos_diego_figueira.pdf

Rosenfeld, A. Os Primeiros judeus de Nova York. In: Judaísmo, Reflexões e Vivências. Perspectiva, 2012.

VInAY, J. P.; DaRbelnet, J. Comparative stylistics of French and English: a methodology for translation. Philadelphia: J. Benjamins Pub., 1995

VenutI, L. Os Escândalos da tradução - por uma ética da diferença. Bauru: Edusc, 2002. 